\section{RMD Open}

Rheumatic \&

Musculoskeletal Diseases

\title{
Human host defence peptide LL37 and anti-cyclic citrullinated peptide antibody in early inflammatory arthritis
}

\author{
Carol A Hitchon, ${ }^{\circledR}$ Xiaobo Meng, Hani S El Gabalawy, Linda Larcombe
}

To cite: Hitchon CA, Meng X, El Gabalawy HS, et al. Human host defence peptide LL37 and anti-cyclic citrullinated peptide antibody in early inflammatory arthritis. RMD Open 2019;5:e000874. doi:10.1136/ rmdopen-2018-000874

- Prepublication history for this paper is available online. To view these files, please visit the journal online (http://dx.doi. org/10.1136/rmdopen-2018000874).

Received 4 December 2018 Revised 26 February 2019 Accepted 14 March 2019
Check for updates

(C) Author(s) (or their employer(s)) 2019. Re-use permitted under CC BY-NC. No commercial re-use. See rights and permissions. Published by BMJ.

University of Manitoba College of Medicine, Winnipeg, Manitoba, Canada

Correspondence to Dr Carol A Hitchon; Carol.Hitchon@umanitoba.ca

\section{ABSTRACT}

Objective Antibodies to citrullinated peptides (anti-CCP) develop in individuals predisposed to rheumatoid arthritis (RA). Neutrophil extracellular traps are a major source of citrullinated antigens and the immunomodulatory host defence peptide LL-37. Vitamin D regulates LL-37 expression. This study assessed the associations of LL-37 and anti-CCP, vitamin D metabolites and vitamin D receptor (VDR) polymorphisms in early inflammatory arthritis (EIA). Methods Serum LL-37, 25-hydroxy-vitamin D (250HvitD) and anti-CCP were measured by ELISA in treatment naïve EIA $(n=181)$. VDR single nucleotide polymorphisms (Fok1, Bsm1, Apa1, Taq1, Cdx-2) and HLADRB1 shared epitope (SE) alleles were detected by DNA amplification. Associations were tested in multivariable models. Median $(25 \%, 75 \%)$ or percentiles are reported.

Results Participants (70\% female, age $56[45,66]$ years, disease activity score [DAS28ESR3var] 3.7 [2.8, 4.8], $41 \%$ anti-CCP positive, $68 \%$ RA) had low serum 250HvitD; $20.5 \mathrm{nmol} / \mathrm{L}(13.9,29.0)$. In multivariable models, controlling for age, sex, SE, smoking and vitamin $\mathrm{D}$ deficiency, LL37 level (top quartile) associated with antiCCP seropositivity (OR 22; 95\% Cl 4 to 104).

Conclusions Levels of circulating LL-37 are associated with anti-CCP seropositivity. LL37 activity may be one mechanism linking infection and toxin exposure to antiCCP generation.

Dysregulated citrullination at articular and extra-articular sites leads to the generation of anti-citrullinated peptide autoantibodies in individuals with genetic susceptibility to rheumatoid arthritis (RA). ${ }^{1}$ One source of citrullinated autoantigens in RA is activated neutrophils which release neutrophil extracellular traps (NETs) in response to infections and toxins. ${ }^{2}$ NETs contain a high concentration of the human host defence peptide cathelicidin (LL-37) ${ }^{3}$ a protein which regulates inflammation and promotes autoimmune responses. ${ }^{4-8}$ However, it is not clear if the formation of autoantibodies to citrullinated proteins is enhanced by LL-37 in RA.

LL-37 expression can be regulated by vitamin $\mathrm{D}$, which is also associated with

\section{Key messages}

What is already known about this subject?

- Human host defence peptide cathelicidin (LL-37) regulates inflammation and promotes autoimmune responses.

What does this study add?

- Circulating LL-37 associates with anti-CCP in early inflammatory arthritis.

- Circulating LL-37 does not associate with serum $25(\mathrm{OH})$ vitamin $\mathrm{D}$ or with common vitamin $\mathrm{D}$ receptor polymorphisms.

How might this impact on clinical practice?

- This suggests LL-37 may have a role in the development of inflammatory arthritis.

autoimmune pathways relevant to RA. ${ }^{9}$ Gene expression of hCAP18, the preproprotein of LL-37, is governed by the vitamin D/vitamin D receptor (VDR) complex. ${ }^{10}$ Even though low serum vitamin D levels and VDR polymorphisms are associated with RA in some populations, ${ }^{11}$ the association of vitamin D mediated expression of LL-37 with pathogenic events in RA remains unclear.

In this study we aimed to delineate the association between LL-37 with antibodies to citrullinated peptides, circulating vitamin D and VDR polymorphisms, in early inflammatory arthritis (EIA).

\section{METHODS}

\section{Study participants}

Participants with inflammatory arthritis for less than 1 year and naive to disease modifying anti-rheumatic drug therapy were recruited from outpatient rheumatology clinics. Patients with RA, ${ }^{12}$ undifferentiated arthritis (UA) (inflammatory arthritis not meeting criteria for defined arthropathy) or spondyloarthropathy (SpA) (predominantly psoriatic arthritis or reactive arthritis) 
were included. Smoking status was assessed by self-report (never, past, current smoker). Arthritis activity was assessed using the disease activity composite score (DAS28ESR3var) and function using the modified health assessment questionnaire (mHAQ).

\section{LL37 and 25-hydroxy vitamin D (25(OH)D)}

Commercial ELISA kits were used to measure the concentrations of LL37 (HK321; Human LL-37 ELISA Kit, Hycult Biotechnology, Uden, the Netherlands) and
25(OH)D (AC-57F1; 25-hydroxy vitamin D, EIA Immunodiagnostic Systems, Scottsdale, Arizona, USA), in DMARD naïve serum samples. Levels are reported as median with $(25 \%, 75 \%$ quartile).

Anti-cyclic citrullinated peptide (anti-CCP) antibody and rheumatoid factor

Anti-CCP2 was measured with a commercial ELISA kit (Inova Diagnostics, San Diego, California, USA) and positivity assessed according to the manufacture's guidelines.

Table 1 Demographics and clinical characteristics of study participants

\begin{tabular}{|c|c|c|c|}
\hline & Rheumatoid arthritis & Undifferentiated arthritis & Spondyloarthropathy \\
\hline $\mathrm{N}$ & 123 & 33 & 25 \\
\hline Age years & $61(52,68)$ & $48(40-53)$ & $46(38.5-56)$ \\
\hline $\operatorname{Sex}(F)$ & $71 \%$ & $88 \%$ & $52 \%$ \\
\hline Anti-CCP ever positive & $80 / 123(65 \%)$ & $2 / 33(6 \%)$ & $1 / 25(4 \%)$ \\
\hline RF and CCP positive & $56 \%$ & $0 \%$ & $0 \%$ \\
\hline HLADRB1 SE positive & $73 / 110(66 \%)$ & $9 / 27(33 \%)$ & $8 / 22(36 \%)$ \\
\hline DAS28ESR3var & $4.4(3.2-5.2)$ & $2.7(1.9-3.8)$ & $3.6(2.9-4.5)$ \\
\hline $\mathrm{mHAQ}$ & $0.5(0.0,0.9)$ & $0.2(0-0.5)$ & $0.5(0.2-1)$ \\
\hline Smoking status & $n=102$ & $n=29$ & $n=20$ \\
\hline Never smoker & $34 \%$ & $31 \%$ & $40 \%$ \\
\hline Ex-smoker & $42 \%$ & $38 \%$ & $35 \%$ \\
\hline Current smoker & $24 \%$ & $31 \%$ & $25 \%$ \\
\hline LL37 ng/mL & $11.8(5.9,24.4)$ & $12.1(4.1-16.0)$ & $11.9(3.5-18.0)$ \\
\hline Serum 25(OH)D mmol/L & $21.5(14.4-31.3)$ & $17.3(12.8-23.2)$ & $19.6(10.9-30.8)$ \\
\hline 25(OH)D deficient (\%) & $60 \%$ & $82 \%$ & $64 \%$ \\
\hline \multicolumn{4}{|c|}{ Vit D receptor polymorphism } \\
\hline \multicolumn{4}{|l|}{ Fokl } \\
\hline $\mathrm{CC}$ & $45 / 118$ & $15 / 33$ & $8 / 24$ \\
\hline CT & $53 / 118$ & $10 / 33$ & $11 / 24$ \\
\hline$\pi$ & $20 / 118$ & $8 / 33$ & $5 / 24$ \\
\hline \multicolumn{4}{|l|}{ Bsm1 } \\
\hline$\pi$ & $28 / 112$ & $8 / 33$ & $4 / 23$ \\
\hline CT & $51 / 112$ & $14 / 33$ & $9 / 23$ \\
\hline $\mathrm{CC}$ & $33 / 112$ & $11 / 33$ & $10 / 23$ \\
\hline \multicolumn{4}{|l|}{ Apa1 } \\
\hline$\pi$ & $26 / 117$ & $5 / 29$ & $6 / 24$ \\
\hline GT & $64 / 117$ & $16 / 29$ & $14 / 24$ \\
\hline GG & $27 / 117$ & $8 / 29$ & $4 / 24$ \\
\hline \multicolumn{4}{|l|}{ Taq1 } \\
\hline$\pi$ & $42 / 117$ & $12 / 29$ & $12 / 24$ \\
\hline $\mathrm{TC}$ & $59 / 117$ & $15 / 29$ & $11 / 24$ \\
\hline CC & $16 / 117$ & $2 / 29$ & $1 / 24$ \\
\hline \multicolumn{4}{|l|}{ Cdx1 } \\
\hline GG & $0 / 52$ & $0 / 14$ & $0 / 14$ \\
\hline GA & $52 / 52$ & $14 / 14$ & $14 / 14$ \\
\hline AA & $0 / 52$ & $0 / 14$ & $0 / 14$ \\
\hline
\end{tabular}

Categorical variables are reported as $\mathrm{n} / \mathrm{N}$ measured (\%), continuous variables are median $(25 \%, 75 \%) \pm$ range. CCP, cyclical citrullinated peptide; RF, rheumatoid factor; SE, shared epitope. 


\begin{tabular}{|c|c|c|}
\hline Model & OR & $95 \% \mathrm{CI}$ OR \\
\hline \multicolumn{3}{|l|}{ Model 1} \\
\hline Age & 1 & $1.0-1.1$ \\
\hline Gender (female) & 1 & $0.4-2.1$ \\
\hline Vitamin D deficient $†$ & 1.4 & $0.7-2.8$ \\
\hline \multicolumn{3}{|l|}{ LL37 } \\
\hline LL37 Q1 & Ref & - \\
\hline LL37 Q2 & 2.7 & $1.0-6.9$ \\
\hline LL37 Q3 & 1.6 & $0.6-4.4$ \\
\hline LL37 Q4 & 6.3 & $2.4-17.0$ \\
\hline
\end{tabular}

\begin{tabular}{lll}
\hline Model 2 & & \\
\hline Age & 1 & $1.0-1.0$ \\
\hline Gender (female) & 0.5 & $0.2-1.5$ \\
\hline $\begin{array}{l}\text { Vitamin D deficient† } \\
\text { Smoking status }\end{array}$ & 2.2 & $0.8-5.9$ \\
\hline \multicolumn{1}{l}{ Never } & Ref & \\
$\quad$ Quit & 2.3 & $0.8-6.6$ \\
\hline Current & 3.4 & $1.0-11.8$ \\
\hline Shared epitope positive & 5.2 & $1.8-14.5$ \\
\hline LL37 & & \\
\hline LL37 Q1 & Ref & \\
\hline LL37 Q2 & 9.1 & $2.0-41.4$ \\
\hline LL37 Q3 & 3.2 & $0.7-14.7$ \\
\hline LL37 Q4 & 22.1 & $4.7-104.1$ \\
\hline
\end{tabular}

*Dependent variableanti-CCP seropositive status.

†Similar findings whenvitamin $D$ status was assessed as vitamin $D$ receptor haplotype (Fokl, Bsm, Apa orTaq).

.$Q$, quartile; ref, reference category.

Rheumatoid factor (RF) was measured by nephelometry in the hospital laboratory and positivity defined as RF titre $>40$ IU.

\section{HLA and VDR genotyping}

HLA-DRB1 typing was performed by PCR using sequence-specific oligonucleotide primers and shared epitope (SE) bearing alleles defined as previously described. ${ }^{13}$ VDR single nucleotide polymorphisms; Bsm1 (B/b (T/C)) (rs1544410), Apa1 (A/a (T/G)) (rs7975232), Taq1 (T/t (T/C)) (rs731236), Fok1 (F/f $(\mathrm{C} / \mathrm{T})) \quad(\mathrm{rs} 10735810)$ and $\mathrm{Cdx}-2$ (G/A) (rs11568820) were amplified from genomic DNA using published protocols and primers as previously described. ${ }^{14}$

\section{Statistical analysis}

Associations of serum LL37 with clinical disease and other parameters were tested using non-parametric methods. We tested the association of LL37 level (quartile) with anti-CCP positivity in logistic regression models. Model covariables were age, sex and vitamin D status measured as $25(\mathrm{OH}) \mathrm{D}$ level (deficient vs not deficient) or VDR. Subsequent models included self reported smoking status and SE status. Statistics were performed using SPSS V.24.

\section{RESULTS}

\section{Study participants}

Demographics, clinical characteristics and laboratory output of participants are shown in table 1 . Study participants were predominantly female $(70 \%)$ with a median (25th quartile; 75th quartile) age of 56 years $(45,66)$ and $68 \%$ met criteria for RA. Nearly half $(41 \%)$ of the participants were seropositive for anti-CCP of which $86 \%$ were also RF seropositive. Only $16 \%$ were seropositive for RF alone (table 1). Disease activity was moderate with median (25th, 75th percentile) DAS28ESR3var 3.7 (2.8, 4.8).

\section{Serum LL-37, 25(OH)D, anti-CCP}

Serum LL37 levels varied widely (median LL37 $11.8 \mathrm{ng}$ / $\mathrm{mL}[5.9,22.3])$ but were similar across RA, UA or SpA (median [25\%, 75\%; range]; $\mathrm{RA} 11.8 \mathrm{ng} / \mathrm{mL}$ [5.9,24.4; 0-2303], UA $12.1 \mathrm{ng} / \mathrm{mL}$ [4.1,16.0; 0-34.7]; SpA 11.9 $\mathrm{ng} / \mathrm{mL}[3.5,18.0 ; 0-4050], \mathrm{p}=0.4$ ) (table 1). Therefore, subsequent analyses combined all three diagnostic categories. All participants had low serum $25(\mathrm{OH}) \mathrm{D}$ (median [25\%, 75\%; range]); 20.5 (20.4 nmol/L [13.6-29; 4.1-63.1]) and $64 \%$ of participants were vitamin D deficient with serum levels of $25(\mathrm{OH}) \mathrm{D}<25 \mathrm{nmol} / \mathrm{L}$. LL37 and $25 \mathrm{OH}$ vitD levels did not correlate (rho $-0.1, \mathrm{p}=0.2$ ). LL37 and anti-CCP2 titres correlated (rho 0.3, p<0.0001).

\section{Multivariable models for independent association of LL-37 with anti-CCP}

We tested the association of serum levels of LL-37 with anti-CCP using logistic regression models controlling for age, sex and vitamin $\mathrm{D}$ deficiency (table 2). Top quartile serum LL-37 was associated with positive anti-CCP status (OR 6.3 [CI 2.4 to 17.0]). The association of LL37 and anti-CCP remained significant when smoking and SE allele status were included in the model. Similar findings were seen when vitamin D status was assessed by VDR genotype, or when models included arthritis diagnosis (data not shown).

\section{Association of LL-37 with clinical variables and VDR polymorphisms}

LL-37 levels did not correlate with clinical disease activity (DAS28ESR3var Spearmans rho 0.07, $\mathrm{p}=0.4$; ESR rho $0.04, \mathrm{p}=0.6$; swollen 28 joint count rho $0.1, \mathrm{p}=0.1$ ), mHAQ (rho 0.03, $\mathrm{p}=0.7$ ) or with self-reported smoking (never $[11.2 \mathrm{ng} / \mathrm{mL} ; 4.9,21.8 ; 0-4050]$, past [11.9 ng/ $\mathrm{mL} ; 7.2,21.8 ; 0-1469.2]$, current [14.2 ng/mL; 8.6, 47.9; 0-2303], Kruskal-Wallis test $\mathrm{p}=0.4$ ). The distribution of VDR polymorphisms (Fok1, BsM1, ApA1, Taq, Cdx1) was similar across the three diagnostic groups (RA, UA and SpA) (table 1) and 25(OH)D levels were similar across the different VDR polymorphisms (data not shown). HLA-DRB1 SE positivity was associated with anti-CCP 
Table 3 Circulating levels of LL-37 based on antibody shared epitope and vitamin D status

\begin{tabular}{|c|c|c|}
\hline Anti-CCP negative & $10.9(4.1,16.7) 0-4050.2$ & $P=0.001$ \\
\hline Anti-CCP positive & $17.1(8.7,43.3) 0-2303.1$ & \\
\hline RF negative & $10.4(3.8,14.3) 0-4050.2$ & $P=0.001$ \\
\hline RF positive & $16.6(8.2,30.5) 0-2303.1$ & \\
\hline \multicolumn{3}{|l|}{ Number of autoantibodies } \\
\hline $\mathrm{RF}$ and anti-CCP negative & $10.4(3.8,13.9) 0-4050.2$ & $P<0.0001$ \\
\hline RF or anti-CCP positive & $10.9(5.4,23.4) 0-1073.4$ & \\
\hline RF and anti-CCP positive & $17.4(9.24,47.7) 0-2303.1$ & \\
\hline Shared epitope positive & $11.8(6.1,23.7) 0-2303$ & $P=0.5$ \\
\hline Shared epitope negative & $10.9(4.1,21.5) 0-4050.2$ & \\
\hline $25(\mathrm{OH}) \mathrm{D}<25 \mathrm{nmol} / \mathrm{L}$ (deficient) & $12.2(7.2,25.3) 0-4050.2$ & $P=0.08$ \\
\hline $25(\mathrm{OH}) \mathrm{D}>25 \mathrm{nmol} / \mathrm{L}$ (adequate) & $10.9(4.1,19.9) 0-1469.2$ & \\
\hline \multicolumn{3}{|l|}{ Smoking status } \\
\hline Never smoked & $11.2(4.9,21.9) 0.1-4050.2$ & $\mathrm{P}=0.4$ \\
\hline Quit smoking & $11.9(7.2,21.8) 0-1469.2$ & \\
\hline Current smoking & $14.2(8.6,47.9) 0-2303.1$ & \\
\hline \multicolumn{3}{|l|}{ Vit D receptor polymorphism } \\
\hline Fokl & $10.6(5.3,24.7) 0-2303$ & $P=1.0$ \\
\hline $\mathrm{CC}$ & $11.9(5.0,21.6) 0.1-4050.1$ & \\
\hline CT & $12.3(6.8,19.4) 0-1469.2$ & \\
\hline \multicolumn{3}{|l|}{ TT } \\
\hline Bsm1 & $11.6(8.5,17.1) 0.2-550.8$ & $P=0.3$ \\
\hline$\pi T$ & $13.4(6.5,23.6) 0-4050.2$ & \\
\hline CT & $9.6(4.1,21.0) 0-1469.2$ & \\
\hline \multicolumn{3}{|l|}{$\mathrm{CC}$} \\
\hline Apa1 & $11.6(7.4,17.1) 0.23-550.8$ & $P=1.0$ \\
\hline$\pi$ & $11.6(5.0,26.0) 0-4050.2$ & \\
\hline GT & $11.9(4.9,22.3) 0-1469$ & \\
\hline \multicolumn{3}{|l|}{$\mathrm{GG}$} \\
\hline Taq1 & $10.2(4.7,22.0) 0-1469.2$ & $P=0.8$ \\
\hline$T$ & $11.9(5.5,23.9) 0-4050.2$ & \\
\hline TC & $12.5(8.8,17.3) 0.2-550.8$ & \\
\hline $\mathrm{CC}$ & & \\
\hline
\end{tabular}

Median (25th, 75th quartile) (range) reported. Statistical significance determined using Man-Whitney U non-parametric two group comparison or Kruskal-Wallis test for three group comparison.

$\mathrm{CCP}$, cyclical citrullinated peptide; RF, rheumatoid factor.

(OR 5.2; CI 1.8 to 14.5) however, no associations were seen between LL-37 and HLA-DRB1 SE or VDR receptor polymorphisms (table 3 ). Similar findings were observed in analyses including only RA subjects (data not shown).

\section{DISCUSSION}

Cathelicidin LL37 expression is associated with anti-CCP seropositivity in patients with DMARD naïve EIA, however, serum LL37 levels do not associate with common VDR polymorphisms, circulating vitamin $\mathrm{D}$ or articular activity.

Several lines of evidence support a role for LL37 in autoimmune disease. ${ }^{15}$ In lupus and psoriasis, LL-37 increases immunogenicity and stability of DNA facilitating plasmacytoid dendritic cell activation. Autoantibodies directed to LL37-DNA complexes are detected in multiple organs of lupus patients. ${ }^{68}$ In psoriasis, LL37 is an autoantigen for pathogenic $\mathrm{T}$ helper cells and circulating levels are elevated over healthy controls but do not correlate with skin activity. ${ }^{16}$ In psoriatic arthritis, synovial fluid has elevated LL37 protein levels and antibodies to carbamylated LL37, but not citrullinated LL37, correlate with articular disease activity. ${ }^{7}$ In RA, LL37 and C1q enhance NET induced macrophage activation, ${ }^{4}$ LL37 protein expression is elevated in serum and synovium ${ }^{1718}$ 
but, as in this report, serum levels of LL37 protein are not correlated with disease activity and neither are antibodies to LL37. ${ }^{18}$ LL37 induces induced osteoblast apoptosis, ${ }^{19}$ suggesting potential to contribute to arthritis associated osteopenia. We report the association of elevated levels of LL37 with anti-CCP seropositivity in EIA.

The observed association of LL-37 with anti-CCP may reflect exposure to infectious or non-infectious factors implicated in RA pathogenesis and host responses. LL37 contributes to innate anti-microbial defences and although it is unclear if LL-37 citrullination occurs in vivo, citrullination of LL37 impairs its anti-infective activities in vitro ${ }^{20}$ potentially increasing bacterial burden. In periodontal disease, a known risk factor for RA, LL37 gingival levels are elevated and RA-like hypercitrullination develops in neutrophils exposed to pore forming toxins produced by A actinomycetemcomitans, a periodontal pathogen associated with ACPA positive RA. ${ }^{21-23}$ Smoking induced damage associated molecular pattern responses are enhanced by LL37 in patients predisposed to non-rheumatic lung disease. ${ }^{24}$ Thus, LL37 may partly mediate immune responses relevant to RA that are induced from interactions between environmental factors and articular or non-articular host tissues.

Vitamin D has multiple effects on immune mechanisms and cellular metabolism potentially relevant for autoimmunity $^{9}$ and is important for LL37 expression. ${ }^{10}$ However, we did not find robust associations of LL37 with serum 25OHvitD or VDR polymorphisms, even though both have been associated with RA in some populations. This may reflect uniform vitamin $\mathrm{D}$ insufficiency in our cohort, the small sample size or the VDR polymorphisms tested. Of the polymorphisms tested only Fok1 leads to functional changes in the receptor whereas the functional implications of the other polymorphisms are less clear; other VDR polymorphisms may be relevant to LL37 expression. However, metabolic stress independent of vitamin D can induce LL37 expression. ${ }^{25}$ Alternatively, preformed LL37, or reduced LL37 degradation, may be sufficient to generate autoimmune responses. Data to support this are needed.

Our study has limitations. Samples were obtained in subjects with new onset arthritis prior to instituting immunomodulatory therapy. In this study, we cannot assess the trajectory of LL37 during the preclinical disease phase or after therapy. Our analysis of serum vitamin D is limited as all participants had low levels. We combined different arthropathies due to small sample sizes however, results were similar when we limited the analysis to only RA. Although the HK321 LL-37 ELISA does not discriminate between LL-37 and the precleaved hCAP18 protein, in general hCAP18 is restricted to intracellular granules thus in circulation the assay reflects LL37 protein.

In this cohort of EIA, cathelicidin (LL37) levels associate with seropositivity to anti-CCP, further supporting the role of LL37 in development of inflammatory arthritis.
Acknowledgements Drs Peschken, Dhindsa and Robinson contributed to recruitment of study participants. Dr Mookherjee assisted with LL-37 assays.

Contributors CAH, LL conceived and designed study. LL, XM conducted assays. CAH, HEG, LL interpreted data and drafted the manuscript. All authors approved final manuscript.

Funding Health Sciences Centre Foundation, Research Manitoba, Manitoba Medical Services Foundation, Canadian Arthritis Network. Canadian Institutes of Health Research (Institute of Musculoskeletal Heath and Arthritis, funding reference no. MOP-133409).

Competing interests Carol Hitchon has received unrelated research funds from Pfizer, UCB Canada.

Patient consent for publication All participants were enrolled with informed consent.

Provenance and peer review Not commissioned; externally peer reviewed.

Data availability statement Select deidentified participant data only from consenting participants available from carol.hitchon@umanitoba.ca

Open access This is an open access article distributed in accordance with the Creative Commons Attribution Non Commercial (CC BY-NC 4.0) license, which permits others to distribute, remix, adapt, build upon this work non-commercially, and license their derivative works on different terms, provided the original work is properly cited, appropriate credit is given, any changes made indicated, and the use is non-commercial. See: http://creativecommons.org/licenses/by-nc/4.0/.

\section{REFERENCES}

1. Darrah $E$, Andrade F. Rheumatoid arthritis and citrullination. Curr Opin Rheumatol 2018;30:72-8.

2. Corsiero E, Pratesi F, Prediletto E, et al. NETosis as source of autoantigens in rheumatoid arthritis. Front Immunol 2016;7.

3. Pinegin B, Vorobjeva N, Pinegin V. Neutrophil extracellular traps and their role in the development of chronic inflammation and autoimmunity. Autoimmun Rev 2015;14:633-40.

4. Ribon M, Seninet S, Mussard J, et al. Neutrophil extracellular traps exert both pro- and anti-inflammatory actions in rheumatoid arthritis that are modulated by $\mathrm{C} 1 \mathrm{q}$ and LL-37. J Autoimmun 2019;98:122-31.

5. Lande R, Chamilos G, Ganguly D, et al. Cationic antimicrobial peptides in psoriatic skin cooperate to break innate tolerance to selfDNA. Eur J Immunol 2015;45:203-13.

6. Gestermann N, Di Domizio J, Lande R, et al. Netting neutrophils activate autoreactive B cells in lupus. J Immunol 2018;200:3364-71.

7. Frasca L, Palazzo R, Chimenti MS, et al. Anti-LL37 antibodies are present in psoriatic arthritis (PSA) patients: new biomarkers in PSA. Frontiers in immunology 1936;2018.

8. Lande R, Gregorio J, Facchinetti V, et al. Plasmacytoid dendritic cells sense self-DNA coupled with antimicrobial peptide. Nature 2007;449:564-9.

9. Dankers W, Colin EM, van Hamburg JP, et al. Vitamin D in autoimmunity: molecular mechanisms and therapeutic potential. Front Immunol 2016;7.

10. Liu PT, Stenger S, Tang DH, et al. Cutting edge: vitamin D-mediated human antimicrobial activity against Mycobacterium tuberculosis is dependent on the induction of cathelicidin. $J$ Immunol 2007;179:2060-3.

11. Bragazzi NL, Watad A, Neumann SG, et al. Vitamin D and rheumatoid arthritis: an ongoing mystery. Curr Opin Rheumatol 2017;29:378-88.

12. Aletaha D, Neogi T, Silman AJ, et al. 3rd, Birnbaum Ns, Burmester GR, Bykerk VP, Cohen MD, et al: 2010 rheumatoid arthritis classification criteria: an American College of Rheumatology/ European League against rheumatism collaborative initiative. Arthritis and rheumatism 2010;62:2569-81.

13. El-Gabalawy HS, Robinson DB, Hart D, et al. Immunogenetic risks of anti-cyclical citrullinated peptide antibodies in a North American native population with rheumatoid arthritis and their first-degree relatives. J Rheumatol 2009;36:1130-5.

14. Larcombe L, Mookherjee N, Slater J, et al. Vitamin D, serum $25(\mathrm{OH})$ $\mathrm{D}, \mathrm{LL}-37$ and polymorphisms in a Canadian First Nation population with endemic tuberculosis. Int J Circumpolar Health 2015;74.

15. Kahlenberg JM, Kaplan MJ. Little peptide, big effects: the role of LL-37 in inflammation and autoimmune disease. J Immunol 2013;191:4895-901.

16. Hwang YJ, Jung HJ, Kim MJ, et al. Serum levels of LL-37 and inflammatory cytokines in plaque and Guttate psoriasis. Mediators Inflamm 2014;2014:1-6. 
17. Kienhöfer D, Hahn J, Schubert I, et al. No evidence of pathogenic involvement of cathelicidins in patient cohorts and mouse models of lupus and arthritis. PLoS One 2014;9:e115474.

18. Hoffmann MH, Bruns H, Bäckdahl L, et al. The cathelicidins LL-37 and rCRAMP are associated with pathogenic events of arthritis in humans and rats. Ann Rheum Dis 2013;72:1239-48.

19. Säll J, Carlsson M, Gidlöf O, et al. The antimicrobial peptide LL37 alters human osteoblast $\mathrm{Ca} 2+$ handling and induces $\mathrm{Ca} 2+-$ independent apoptosis. J Innate Immun 2013;5:290-300.

20. Koziel J, Bryzek D, Sroka A, et al. Citrullination alters immunomodulatory function of LL-37 essential for prevention of endotoxin-induced sepsis. J Immunol 2014;192:5363-72.

21. Engström M, Eriksson K, Lee L, et al. Increased citrullination and expression of peptidylarginine deiminases independently of $P$. gingivalis and $\mathrm{A}$. actinomycetemcomitans in gingival tissue of patients with periodontitis. $J$ Trans/ Med 2018;16.
22. Grant M, Kilsgård O, Åkerman S, et al. The human salivary antimicrobial peptide profile according to the oral microbiota in health, periodontitis and smoking. J Innate Immun 2018:1-12.

23. Konig MF, Abusleme L, Reinholdt J, et al. Aggregatibacter actinomycetemcomitans-induced hypercitrullination links periodontal infection to autoimmunity in rheumatoid arthritis. Sci Trans/ Med 2016;8.

24. Pouwels SD, Hesse L, Faiz A, et al. Susceptibility for cigarette smoke-induced dAMP release and DAMP-induced inflammation in COPD. Am J Physiol Lung Cell Mol Physiol 2016;311:L881-L892.

25. Park K, Ikushiro H, Seo HS, et al. ER stress stimulates production of the key antimicrobial peptide, cathelicidin, by forming a previously unidentified intracellular S1P signaling complex. Proceedings of the National Academy of Sciences 2016;113:E133 4-E1342. 